\title{
Study of changing statistics model's influence on the exploitation and conformity of results in the new standard version ISO 14644 part 1.
}

\author{
Lamkharbach Yassine $^{{ }^{*}}$, Bazi Fathallah ${ }^{1}$, Haji Latifa ${ }^{1}$, Bennani Laila $^{1}$, Mourran Aicha ${ }^{1}$, Bouamrani \\ Mouna Latifa ${ }^{1}$, \\ ${ }^{1}$ Department of Chemistry, Laboratory of Analytical Chemistry and Physico-Chemistry of Materials (LACPCM), Faculty of Science \\ Ben Msik, Hassan II University
}

\section{Article Info}

Received August 14, 2018

Keyword:
Qualification
ISO 14644 part 1
Normal law
hypergeometric law
Particle concentration
cleanroom
Classification.

\begin{abstract}
Recently, the first two parts of the standard ISO 14644-1 and 2 were updated This followed a 9-year process of revision. The standard is applicable across several industries covering healthcare, pharmaceuticals and electronics; and it outlines the approach for the design, classification and operation of cleanrooms. This article assesses the influence of the changing ISO 14644-1 on the conformity of the results. The initial version of Part 1 was based on the wrong hypothesis of a Gaussian distribution of particle concentration (in reality, the spatial distribution of particles is random). It is a hypergeometric model that has been selected for the revision of this standard. If you have seen in the standard ISO 14644-1 of 1999 you will notice that all the calculations are made according to the normal law, like the average, the mean of the averages, the standard deviation and $95 \%$ upper confidence limit... then in reality the distribution of the particles in the air in a cleanroom it's random, for this reason in this new version, it is a hypergeometric model that has been selected for the revision of this standard. In this article we have given a comparison between the two versions of the standard ISO 14644 part 1 and then it has been demonstrated by real case studies that the old version of the standard was based on the wrong hypothesis. After the comparison and study that we have done we encountered a contradiction among two versions of the standard IOS14644-1 (1999 and 2015), that we have treated in the same room, by the end of this experiment we drew out that the room is declared compliant in the new version 2015 and not compliant in the old version 1999, which aroused our curiosity to detect the error in the old version by this real case study.
\end{abstract}

\section{Corresponding Author:}

Lamkharbach Yassine,

Department of Chemistry, Laboratory of Analytical Chemistry and Physico-Chemistry of Materials

(LACPCM),

Faculty of Sciences Ben M'sik, Hassan II University,

Av Driss El HartiSidiOthmane Casablanca B.P 7955, Maroc

Email: lamkharbachyassine@gmail.com

\section{Introduction}

To put the new standard in context, ISO 14644 is a set of cleanroom standards (for which there are currently 12 active parts, in addition to the draft discussed in this article). The first part of the standard to appear was for the classification of cleanrooms in relation to particle air cleanliness, which was issued in 1999 (and subsequently revised in 2015).2 The ISO 14644 standard can be applied to any industry. However, its foremost application is in the electronics and semiconductor industries. The initial version of Part 1 was based on the wrong hypothesis of a Gaussian distribution of particle concentration (in reality, the spatial distribution of particles is random). It is a hypergeometric model that has been selected for the revision of this standard. If you have seen in the standard ISO 14644-1 of 1999 you will notice that all the calculations are made 
according to the normal law, like the average, the mean of the averages, the standard deviation and $95 \%$ upper confidence limit... then in reality the distribution of the particles in the air in a cleanroom it's random, for this reason in this new version, it is a hypergeometric model that has been selected for the revision of this standard. In this article reviews, we have given a comparison between the two versions of the standard ISO 14644 part 1 and then it has been demonstrated by real case studies that the old version of the standard was based on the wrong hypothesis. After the comparison and study that we have done we encountered a contradiction among two versions of the standard IOS14644-1 (1999 and 2015), that we have treated in the same room, by the end of this experiment we drew out that the room is declared compliant in the new version 2015 and not compliant in the old version 1999, which aroused our curiosity to detect the error in the old version by this real case study.

1. Visual Servoing the main changes in the new revision of iso 14644 part 12015 :

1.2 The table of ISO classes, with in addition the removal of the threshold value in ISO 5 (29 particles / $\mathrm{m}^{3}$ ) for the particle size $5 \mu \mathrm{m}$ :

The first change of the standard ISO 14644-1 is the remove of the 5 micron particle sizes threshold values for the ISO 5 class (see: Table 1\&2).

Table 1: ISO 14644-1:1999 - Cleanrooms and associated controlled environments- Part 1: Classification of air cleanliness.

\begin{tabular}{|c|c|c|c|c|c|c|}
\hline \multirow{2}{*}{$\begin{array}{l}\text { ISO class } \\
\text { Number }(\mathbf{N})\end{array}$} & \multicolumn{6}{|c|}{$\begin{array}{l}\text { Maximum allowable concentrations }\left(\text { particles } / \mathbf{m}^{3}\right) \text { for particles equal to end greater } \\
\text { than the considered sizes, shown below }\end{array}$} \\
\hline & $0,1 \mu \mathrm{m}$ & $0,2 \mu \mathrm{m}$ & $0,3 \mu \mathrm{m}$ & $0,5 \mu \mathrm{m}$ & $1 \mu \mathrm{m}$ & $5 \mu \mathrm{m}$ \\
\hline ISO Class 1 & 10 & 2 & & & & \\
\hline ISO Class 2 & 100 & 24 & 10 & 4 & & \\
\hline ISO Class 3 & 1000 & 237 & 102 & 35 & 8 & \\
\hline ISO Class 4 & 10000 & 2370 & 1020 & 352 & 83 & \\
\hline ISO Class 5 & 100000 & 23700 & 10200 & 3520 & 832 & 29 \\
\hline ISO Class 6 & 1000000 & 237000 & 102000 & 35200 & 8320 & 293 \\
\hline ISO Class 7 & & & & 352000 & 83200 & 2930 \\
\hline ISO Class 8 & & & & 3520000 & 832000 & 29300 \\
\hline ISO Class 9 & & & & 35200000 & 8230000 & 293000 \\
\hline
\end{tabular}

The table of Classification of air cleanliness by particle concentration of ISO 14644-1: 2015 (table 2), describes the maximum allowable concentrations for each particle size. The values have not been modified, but some values have been removed from the table, in particular. 
Table 2: ISO 14644-1:2015 - Cleanrooms and associated controlled environments - Part 1: Classification of air cleanliness by particle concentration.

\begin{tabular}{|c|c|c|c|c|c|c|}
\hline \multirow{2}{*}{$\begin{array}{l}\text { ISO class } \\
\text { Number }(N)\end{array}$} & \multicolumn{6}{|c|}{$\begin{array}{l}\text { Maximum allowable concentrations ( particles } / \mathrm{m} 3 \text { ) for particles equal to end greater than } \\
\text { the considered sizes, shown below }{ }^{\mathrm{a}}\end{array}$} \\
\hline & $0,1 \mu m$ & $0,2 \mu m$ & $0,3 \mu m$ & $0,5 \mu m$ & $1 \mu m$ & $5 \mu m$ \\
\hline ISO Class 1 & $10^{\mathrm{b}}$ & d & $\mathrm{d}$ & d & $\mathrm{d}$ & $\mathrm{e}$ \\
\hline ISO Class 2 & 100 & $24^{\mathrm{b}}$ & $10^{\mathrm{b}}$ & d & d & $\mathrm{e}$ \\
\hline ISO Class 3 & 1000 & 237 & 102 & $35^{\mathrm{b}}$ & $\begin{array}{l}d \\
\end{array}$ & $\mathrm{e}$ \\
\hline ISO Class 4 & 10000 & 2370 & 1020 & 352 & $83^{\mathrm{b}}$ & $\mathrm{e}$ \\
\hline ISO Class 5 & 100000 & 23700 & 10200 & 3520 & 832 & d, e, $\mathbf{f}$ \\
\hline ISO Class 6 & 1000000 & 237000 & 102000 & 35200 & 8320 & 293 \\
\hline ISO Class 7 & $\mathrm{c}$ & $\mathrm{c}$ & $\mathrm{c}$ & 352000 & 83200 & 2930 \\
\hline ISO Class 8 & c & c & c & 3520000 & 832000 & 29300 \\
\hline ISO Class 9 & $\mathrm{c}$ & $\mathrm{c}$ & $\mathrm{c}$ & 35200000 & 8230000 & 293000 \\
\hline \multicolumn{7}{|c|}{ 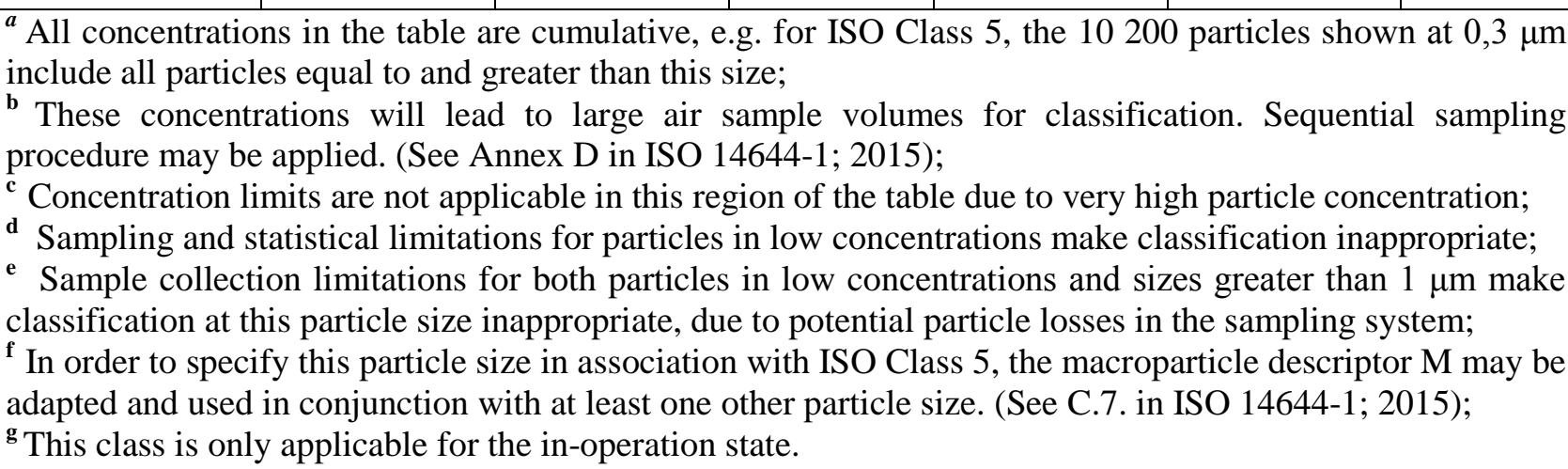 } \\
\hline
\end{tabular}

As a comparison, the new classification table from ISO 14644-1:2015 is shown above:

\section{- Raison for this removal of 5 um particle size:}

For consistency with the uncertainties of measurement counts, it is envisaged remove from the table all lower concentration values to 10 parts $/ \mathrm{m}^{3}$. The attention of users should be drawn to the need to collect volumes important for the weak class limit values. The behavior of these particles size (which tend to sediment), associated with a low concentration, leads to a level of uncertainty in the counts that renders this value unsuitable for classification.

\section{The new method for the determination of the number of sampling locations:}

In the old version of the standard ISO 14644-1 of 1999, we deduce the minimum number of sampling points according to this following expression given by the standard ISO 14644-1 of 1999:

Where:

$$
N L=\sqrt{ } A
$$

$\mathbf{N}_{\mathbf{L}}$ : Is the minimum number of sampling locations to be evaluated, rounded up to the next whole number;

A: is the area of the cleanroom in $\mathrm{m}^{2}$.

But in this new version of ISO 14644-1 of 201, no calculations are required to determine the number of locations, for the determination of the number of sampling locations; a new table has been developed with two cases: 
- When the area of the cleanroom or clean zone is less than $1000 \mathrm{~m}^{2}$ you have to use this table,

- When the area of the cleanroom or clean zone is greater than $1000 \mathrm{~m}^{2}$, apply the formula (2) to determine the minimum number of sampling locations required.

$$
\mathrm{N}_{\mathrm{L}}=27 \times\left(\frac{\mathrm{A}}{1000}\right)
$$

Where:

$\mathbf{N}_{\mathbf{L}}$ : Is the minimum number of sampling locations to be evaluated, rounded up to the next whole number;

$\mathbf{A}$ : is the area of the cleanroom in $\mathrm{m}^{2}$.

Table 3: Sampling locations related to cleanroom area according to ISO 14644 part 1 of 2015.

\begin{tabular}{|c|c|}
\hline Area of cleanroom $\left(\mathrm{m}^{2}\right)$ less than or equal to & $\begin{array}{l}\text { Minimum number of sampling locations to be } \\
\text { tested }\left(N_{L}\right)\end{array}$ \\
\hline 2 & 1 \\
\hline 4 & 2 \\
\hline 6 & 3 \\
\hline 8 & 4 \\
\hline 10 & 5 \\
\hline 24 & 6 \\
\hline 28 & 7 \\
\hline 32 & 8 \\
\hline 36 & 9 \\
\hline 52 & 10 \\
\hline 56 & 11 \\
\hline 64 & 12 \\
\hline 68 & 13 \\
\hline 72 & 14 \\
\hline 76 & 15 \\
\hline 104 & 16 \\
\hline 108 & 17 \\
\hline 116 & 18 \\
\hline 148 & 19 \\
\hline 156 & 20 \\
\hline 192 & 21 \\
\hline 232 & 22 \\
\hline 276 & 23 \\
\hline 352 & 24 \\
\hline 436 & 25 \\
\hline 636 & 26 \\
\hline 1000 & 27 \\
\hline$>1000$ & See Forumla (2) \\
\hline \multicolumn{2}{|c|}{$\begin{array}{l}\text { NOTE } 1 \text { If the considered area falls between two values in the table, the greater of the two should be } \\
\text { selected. } \\
\text { NOTE } 2 \text { In the case of unidirectional airflow, the area may be considered as the cross section of the moving } \\
\text { air perpendicular to the direction of the airflow. In all other cases the area may be considered as the } \\
\text { horizontal plan area of the cleanroom or clean zone. }\end{array}$} \\
\hline
\end{tabular}




\section{- The influence of this change:}

For the new version the number of sampling points has been increased compared to the old version, this increase is intended to increase the confidence interval.

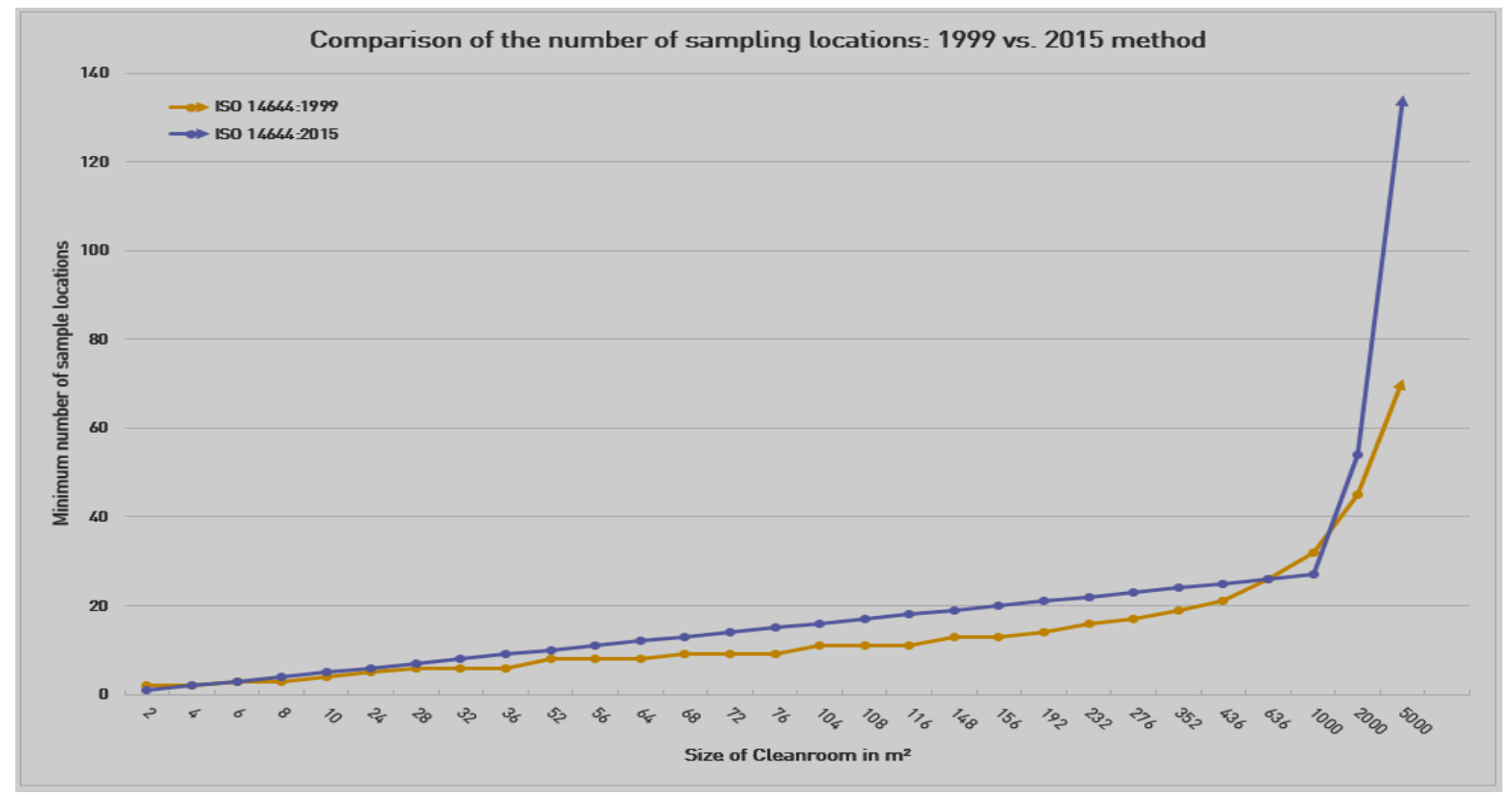

Figure 1: Graphical representation of comparison of the number of sampling locations: 1999 vs 2015 method.

\section{The removal of the $95 \%$ upper confidence limit (UCL) calculations in the new version :}

In the old version the compliance was based on the 95\% upper confidence limit (UCL), relying on three different rules depending on the area of the cleanroom or the clean zone.

- In the first case: if there is only one sampling location, the standard requires three measurements at that location.

- In the second case: if there are two to nine sampling locations, the average at each location is calculated (possibly as a single measurement is allowed), then the mean of the averages of the different locations is calculated. Finally, a 95\% upper confidence limit (UCL) is calculated on this mean of the averages. The cleanroom or the clean zone is considered compliant according to the old version of the standard ISO 14644-1 (1999) if:

a- Each calculated average is consistent,

b- The mean of the averages, with its $95 \%$ upper confidence limit, is compliant.

- In the third case: when the number of the sampling location is more than ten, the average of the values at each location must compliant with the specified limit.

\section{- The raison for removal of the 95\% upper confidence limit (UCL) calculations:}

The statistical model by definition applies or it does not apply, it cannot be modulated, and the robustness of a statistical model is its ability not to be modified by a small modification in the data or in the parameters of the model chosen for the estimation. Therefore we reject the compliance of a cleanroom or a clean zone because some points are much cleaner than the specified limit, which is illogical.For this reason, we find in this new version of the standard ISO 14644, another statistical model, it is the hypergeometric law, perfectly known on the mathematical plane. This new statistical model (the hypergeometric law) aiming to establish with at least 95\% confidence that at least $90 \%$ of the sample points will be compliant (concentration at each point below the limit concentration for each specified size). This operation, which now makes it possible to check at each sampling, is compliant or non-compliant. 


\section{The proposed improvements for this standard is :}

To facilitate and standardize the results in the industries for the calculation of the volume that requires the application of the equations, it is better to put a table with a volume specified for each class ISO. The advantage of this table makes it possible to minimize the uncertainty in the companies because with the increase of the volume finds, one can deceive in the error. Therefore to avoid this doubt I built a table which gathers all the classes ISO given by this standard ISO 14644-1.

The sample volume can be calculated from expresion as follows:

$$
V s=\left(\frac{20}{\mathrm{C}_{\mathrm{n}, \mathrm{m}}}\right) \times 100
$$

$\boldsymbol{V} \boldsymbol{s}$ : is the minimum single sample volume per location, expressed in litres

$\mathbf{C}_{\mathbf{n}, \mathbf{m}}$ : is the class limit (number of particles per cubic metre) for the largest considered particle size specified for the relevant class.

20: is the number of particles that could be counted if the particleconcentration were at the class limit.

Table 4: Sampling volume per class.

\begin{tabular}{|c|c|c|c|c|c|c|}
\hline \multirow[t]{2}{*}{$\begin{array}{l}\text { ISO class } \\
\text { Number }(\mathrm{N})\end{array}$} & \multicolumn{6}{|c|}{$\begin{array}{l}\text { Maximum allowable concentrations ( particles/m3) for particles equal to end greater than the } \\
\text { considered sizes, shown below }\end{array}$} \\
\hline & $0,1 \mu \mathrm{m}$ & $0,2 \mu \mathrm{m}$ & $0,3 \mu \mathrm{m}$ & $0,5 \mu \mathrm{m}$ & $1 \mu \mathrm{m}$ & $5 \mu \mathrm{m}$ \\
\hline ISO Class 1 & $\mathbf{V s}=2000 \mathrm{~L}$ & & & & & \\
\hline ISO Class 2 & $\mathbf{V s}=200 \mathrm{~L}$ & $\mathbf{V s}=833.33 \mathrm{~L}$ & $\mathbf{V s}=2000 \mathrm{~L}$ & & & \\
\hline ISO Class 3 & $\mathbf{V s}=20 \mathrm{~L}$ & $\mathrm{Vs}=73.26 \mathrm{~L}$ & $\mathbf{V s}=196.09 \mathrm{~L}$ & $\mathbf{V s}=571.43 \mathrm{~L}$ & - & \\
\hline ISO Class 4 & $V s=2 \mathrm{~L}$ & $\mathbf{V s}=7.3260 \mathrm{~L}$ & $\mathrm{Vs}=19.61 \mathrm{~L}$ & $\mathrm{Vs}=56.82 \mathrm{~L}$ & $\mathbf{V s}=240.96 \mathrm{~L}$ & \\
\hline ISO Class 5 & $\mathbf{V s}=2 \mathrm{~L}$ & $\mathbf{V s}=0.733 \mathrm{~L}$ & $\mathrm{Vs}=1.96 \mathrm{~L}$ & $\mathrm{Vs}=5.68 \mathrm{~L}$ & $\mathbf{V s}=24.04 \mathrm{~L}$ & \\
\hline ISO Class 6 & $\mathbf{V s}=2 \mathrm{~L}$ & $\mathbf{V s}=2 \mathrm{~L}$ & $\mathbf{V s}=2 \mathrm{~L}$ & $\mathbf{V s}=2 \mathrm{~L}$ & $\mathrm{Vs}=2.40 \mathrm{~L}$ & $\mathbf{V s}=68.26 \mathrm{~L}$ \\
\hline ISO Class 7 & & & & $\mathrm{Vs}=2 \mathrm{~L}$ & $V s=2 L$ & $\mathbf{V s}=6.83 \mathrm{~L}$ \\
\hline ISO Class 8 & & & & $\mathbf{V s}=2 \mathrm{~L}$ & $\mathbf{V s}=2 \mathrm{~L}$ & $\mathrm{Vs}=2 \mathrm{~L}$ \\
\hline ISO Class 9 & & & & $\mathbf{V s}=2 \mathrm{~L}$ & $\mathbf{V s}=2 \mathrm{~L}$ & $\mathbf{V s}=2 \mathrm{~L}$ \\
\hline
\end{tabular}

To confirm the use of this table is its role to minimize the time and standardization of the data I will give you an example.

Example: A cleanroom has a floor area of $9 \mathrm{~m}^{2}$ and is specified to be ISO Class 3 in operation.

Either a particle counter having $50.0 \mathrm{~L}$ per minute as a flow rate, and the classification should be performed using this particle counter, therefore the particle size considered is $(\mathrm{D} \geq 0.1 \mu \mathrm{m})$

The number of sampling locations, $N \mathrm{~L}$ for an arear with $9 \mathrm{~m}^{2}$, is determined to be five, based on Table 3 .

The particle concentration limit for ISO Class 3 at $\geq 0,1 \mu \mathrm{m}$ is taken from

$C n(\geq 0,1 \mu \mathrm{m})=1000$ particles/m3

The required single sample volume can be calculated from the expression as follows:

$$
V s=\left(\frac{20}{C_{n, m}}\right) \times 100
$$

$V s=\left(\frac{20}{1000}\right) \times 100$

$V s=(0,02) \times 1000$

$V s=20$ litres

So if you have compared the volume found with it give in the table you will find the same result, so instead of making calculations and increases it will be easy and useful to work with this table. 


\section{Experimental part:}

To study the influence of this change, we have worked on a cleanroom whose space is equal to $9 \mathrm{~m}^{3}$, so the minimum number of the sampling locations to be tested $\left(N_{L}\right)$ is 3 sampling locations according to the standard ISO 14644-1 (1999) and 5 sampling locations accordingto the standard ISO 14644-1 (2015),

\subsection{Worked examples of classification calculations according to the standard ISO 14644-1 (1999):}

Example: A cleanroom has a floor area of $9 \mathrm{~m}^{2}$ and is specified to be ISO Class 5 in operation.

One particle size is considered: $D \geq 0,5 \mu \mathrm{m}(3520)$.

\section{4-1-1 The first thing that needs to be determined is :}

a- Sampling locations :

Sampling locations $=\sqrt{ }$ Area of cleanroom $(\mathrm{m} 2)=\sqrt{9}=\mathbf{3}$ sampling locations to be tested

\section{$b$ - Position of counters:}

To align with GMP (Good Manufacturing Practices), the location should be orientated to the point of greatest risk e.g. close to fixed equipment. The standard recommends that the following is accounted for:

- Room layout;

- Equipment layout;

- Airflow patterns;

- Position of air supply and return vents;

- Air-change rates;

- Consideration should be given to any unintended bias in the sampling process.

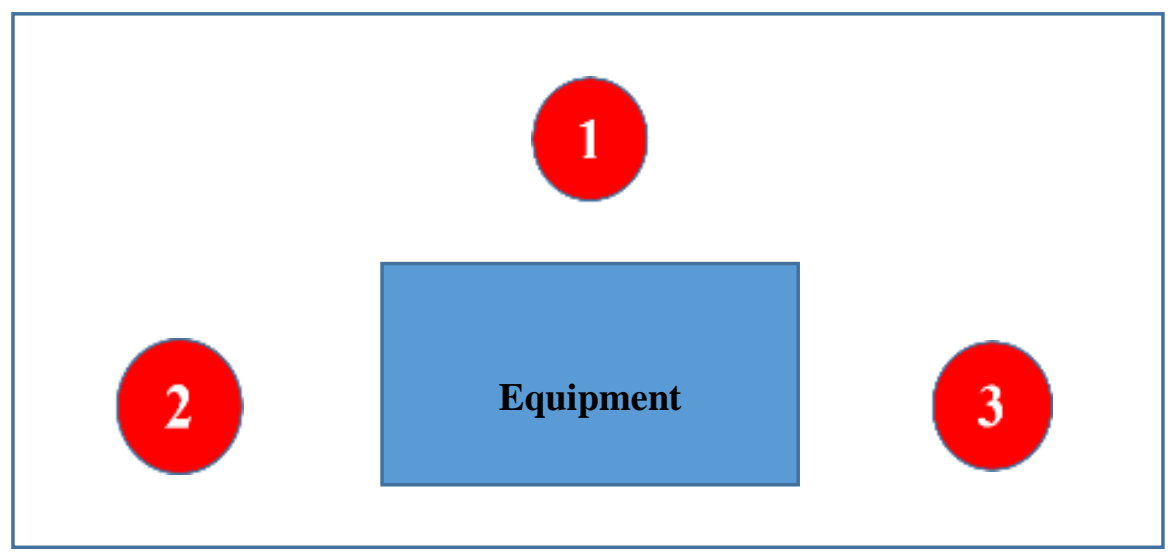

Figure 2: Sampling locations in cleanroom for the first case.

\section{4-1-2 Statistical treatment of particle concentration data according to the standard NF EN ISO 14644} part 1 of 1999 :

a- Algorithm for computation of average particle concentration at a location ( $\bar{x} i)$ :

The calculation of the average particle concentration should be done at each sampling point, applying equation (3):

$$
\bar{x} i=\frac{x i .1+x i .2+\cdots+x i . n}{\mathrm{n}}
$$

Where:

$\bar{x} i \quad$ is the average particle concentration at one location;

xi.1 à $x i . n \quad$ are the particle concentrations of the individual samples;

$n \quad$ is the number of samples taken at the location. 
b- Algorithms for computation of $95 \%$ upper confidence limit:

b.1 Mean of the averages $\overline{\bar{x}}$

En appliquant l'équation (4), déterminer la moyenne générale.

Where:

$$
\overline{\overline{\mathrm{x}}}=\frac{\bar{x} i .1+\bar{x} i .2+\cdots+\bar{x} i . m}{\mathrm{~m}}
$$

$\overline{\bar{X}}$ is the mean of the averages;

$\bar{x} i .1$ à $\bar{x} i . m$ are individual location averages;

$m$ is the number of individual location averages.

\section{b.2 Standard deviation of the mean (S):}

$$
\mathrm{S}=\sqrt{\frac{(\bar{x} i \cdot 1-\overline{\overline{\mathrm{x}}})+(\bar{x} i .2-\overline{\overline{\mathrm{x}}})+\cdots+(\bar{x} i \cdot m-\overline{\overline{\mathrm{x}}})}{\mathrm{m}-1}}
$$

Where:

$\mathbf{S}$ is the standard deviation of means at sampling points.

Using equation (5), determine the standard deviation of the means at the sampling points.

\section{b.3 Computation of $95 \%$ upper confidence limit for mean of the averages}

Applying the equation (6), for the determination of 95\% upper confidence limit for the mean averages.

Where:

$$
\mathbf{9 5 \%} \mathbf{U C L}=\overline{\overline{\mathrm{x}}}+\mathrm{t}_{0.95}\left(\frac{s}{\sqrt{m}}\right)
$$

$t_{0,95}$ is student's t factor, which is dependent on the number of individual averages, and guarantees with $95 \%$ confidence that all individual averages are within the computed UCL.

The values of the $\mathrm{t}$ factor for $95 \% \mathrm{UCL}$ are given in table 4.

Table 5: Student's t factor for 95\% upper confidence limit 14644-1 (1999).

\begin{tabular}{|c|c|c|c|c|c|c|}
\hline $\begin{array}{c}\text { Number of } \\
\text { individual averages }\end{array}$ & 2 & 3 & 4 & 5 & 6 & 7 à 9 \\
\hline $\boldsymbol{t}_{\mathbf{0 , 9 5}}$ & 6,3 & 2,9 & 2,4 & 2,1 & 2,0 & 1,9 \\
\hline
\end{tabular}

Sampling data for particles $\geq 0.5 \mu \mathrm{m}$ expressed according to the standard NF EN ISO 14644 part 1 of 1999 :

Table 6: Sampling data for particles $\geq 0,5 \mu \mathrm{m} 14644-1$ (1999).

\begin{tabular}{|c|c|c|c|}
\hline Points & $\mathbf{1}$ & $\mathbf{2}$ & $\mathbf{3}$ \\
\hline $\bar{x} \mathrm{x}:$ Average & $\mathbf{3 5 0 0}$ & $\mathbf{2 1 4 0}$ & $\mathbf{3 4 8 0}$ \\
\hline$\overline{\bar{x}}$ : Mean of the averages & \multicolumn{3}{|c|}{$\mathbf{3 0 4 0}$} \\
\hline S : Standard deviation of the mean & $\mathbf{7 7 9}$ \\
\hline $\mathbf{t}_{\mathbf{0 . 9 5}}$ : Student's t factor & $\mathbf{2 . 9}$ \\
\hline UCL 95\% : upper confidence limit & \multicolumn{3}{|c|}{ N040+2.9 $(\mathbf{7 7 9} \sqrt{ } \mathbf{3})=\mathbf{4 3 4 4}$} \\
\hline Result & NOT COMPLIANT \\
\hline
\end{tabular}




\section{Interpretation of results:}

As you can see, the results are all below the specified limit (3520), while the room is declared not-compliant, because a single point that is too clean (point 2), which is illogical. This is the well-known case of "points too clean".

To study the influence of this change, we treated the same previous example but with the new version of ISO 14644-1 2015,

4.2 Worked examples of classification calculations according to the standard ISO 14644-1 (2015):

The number of the sampling locations $\mathrm{N}_{\mathrm{L}}$, is determined to be five, based on Table 3 is 5 sampling locations.

5

2

\section{1}

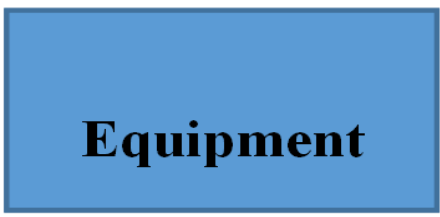

\section{4}

3

Figure 3: Sampling locations in cleanroom for the first case.

Table 7: Sampling data for particles $\geq 0.5 \mu \mathrm{m}$ ISO 14644 part 1 of 2015 .

\begin{tabular}{|c|c|c|c|c|c|}
\hline $\begin{array}{c}\text { Sampling } \\
\text { location }\end{array}$ & $\begin{array}{c}\text { Sample 1 } \\
x_{i} \geq 0,5 \mu \mathrm{m} \\
\text { counts per } \\
50,01)\end{array}$ & $\begin{array}{c}\text { Location sample } \\
\text { average } \\
\text { (counts per 50.01) }\end{array}$ & $\begin{array}{c}\text { Location } \\
\text { averagentration } \\
m^{3}=\text { counts per } \\
\text { average } \times 20)\end{array}$ & $\begin{array}{c}\text { ISO Class 3 } \\
\text { limit for } \geq 0,5 \\
\mu m \text { particle size }\end{array}$ & $\begin{array}{c}\text { Pass / } \\
\text { fail }\end{array}$ \\
\hline 1 & 175 & 175 & 3500 & 3520 & Pass \\
\hline 2 & 107 & 107 & 2140 & 3520 & Pass \\
\hline 3 & 174 & 174 & 3480 & 3520 & Pass \\
\hline 4 & 44 & 44 & 880 & 3520 & Pass \\
\hline 5 & 172 & 172 & 3440 & 3520 & Pass \\
\hline
\end{tabular}

\section{Interpretation of results:}

Each value of the concentration for $\mathrm{D} \geq 0,5 \mu \mathrm{m}$ is less than the limit of 10200 particles/m3, Therefore, the air cleanliness by particle concentration of the cleanroom meets the required ISO Class. After the study that we have done we encountered a contradiction among two versions of the standard IOS14644-1 (1999 and 2015), that we have treated in the same room, by the end of this experiment we drew out that the room is declared compliant in the new version 2015 and not compliant in the old version 1999, which aroused our curiosity to detect the error in the old version by this real case study. 
So the initial version of Part 1 was based on the wrong hypothesis of a Gaussian distribution of particles concentration (Figure 4\&5).

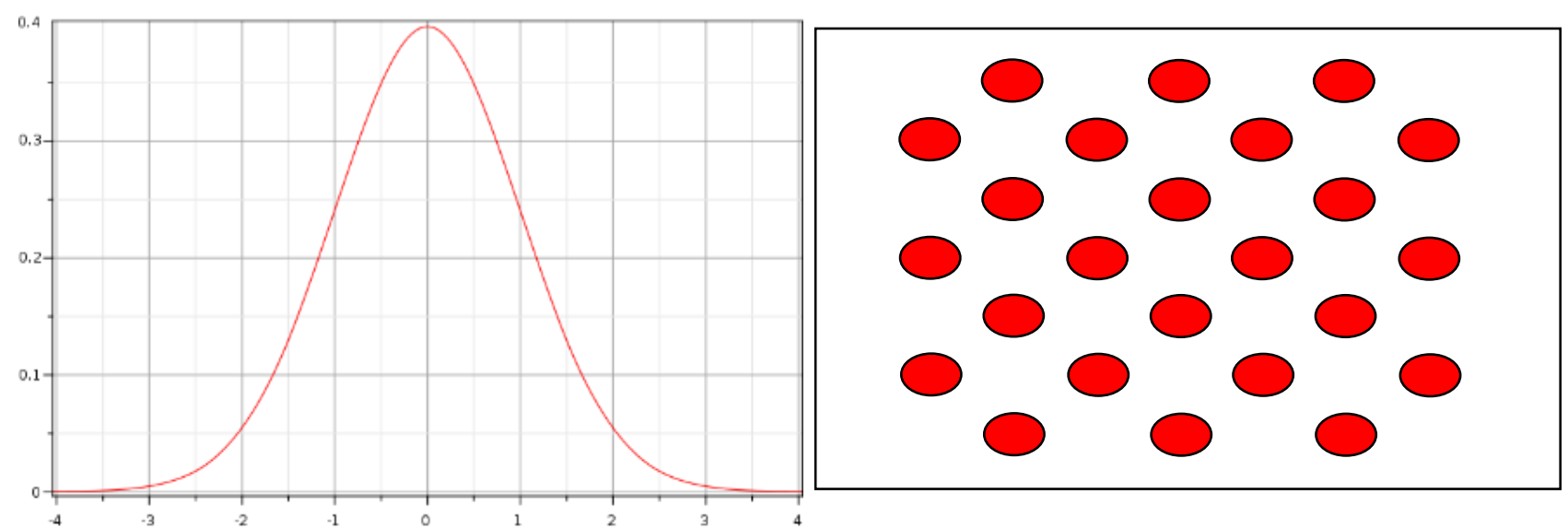

Figure 4: The Curve and the distribution of Gauss law of particles concentration in the cleanroom.

But in reality, the spatial distribution of particles is random (Figure 6\&7). It is a hypergeometric model that has been selected for the revision of this standard.
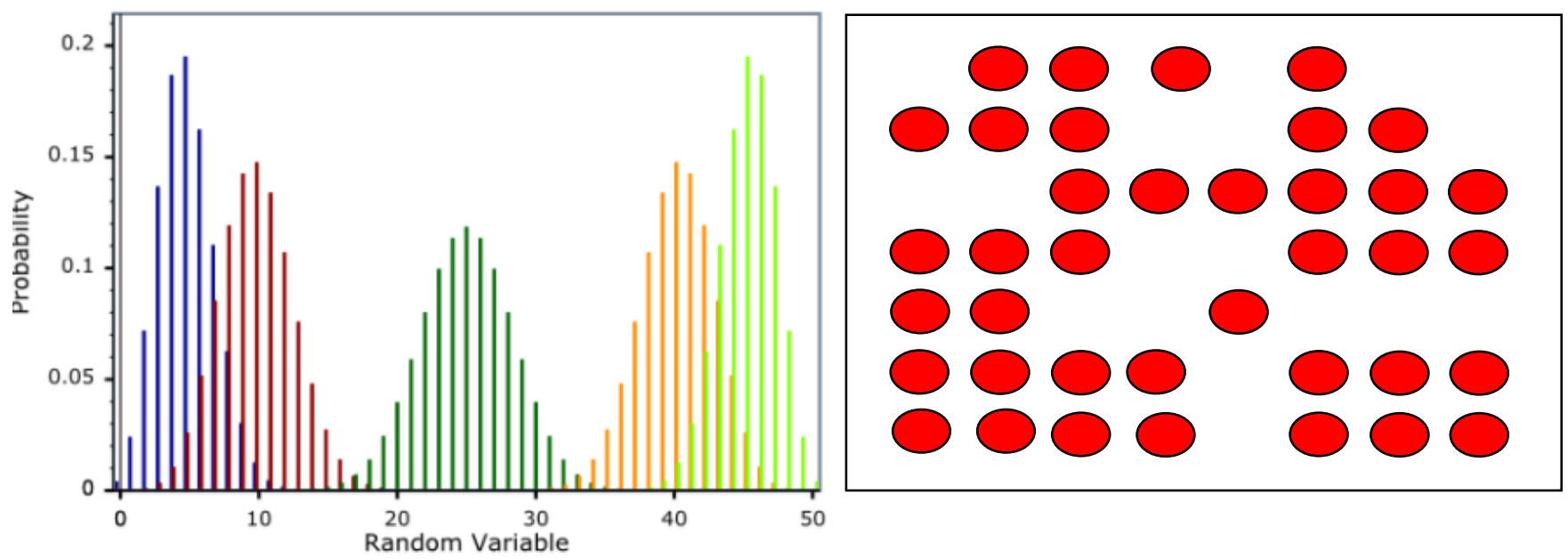

Figure 5: The curve of and distribution of hypergeometric law of particles concentration in the cleanroom.

If you have seen in the standard ISO 14644-1 of 1999 you will notice that all the calculations are made according to the normal law, like the average, the mean of the averages, the standard deviation and $95 \%$ upper confidence limit... then in reality the distribution of the particles in the air in a clean room it's random for this reason in the new version in this ISO 14644-1 version 2015, they have corrected.

\section{CONCLUSION:}

In this article we have studied the influence of the change of statistical model on the exploitation and the conformity of the results and we have given a comparison between the two versions of the standard ISO 146644 part 11999 and 2015, then it has been demonstrated by real case studies that the old version of this standard was based on the wrong hypothesis. To show that the distribution of particles in space is not homogeneous, and the old model is not able to cover all cases in terms of the number of locations ( 1 point, 3 points, 9 points, etc.).We have worked on a cleanroom whose space is equal to 9 square meters, so the minimum number of the sampling locations to be tested (NL) is 3 sampling locations according to the standard ISO 14644-1 (1999) and 5 sampling locations according to the standard ISO 14644-1 (2015).After the comparison and study that we have done we encountered a contradiction among two versions of the standard IOS14644-1 (1999 and 2015), that we have treated in the same room, by the end of this experiment we drew out that the room is declared compliant in the new version 2015 and not compliant in the old version 1999 , which aroused our curiosity to detect the error in the old version by this real case study. 


\section{References}

[1] International Organization for Standardization. ISO 14644-1 Cleanrooms and Associated Controlled Environments - Part 1: Classification of Air Cleanliness. Geneva, Switzerland: ISO;2015, 44p.

[2] International Organization for Standardization. ISO 14644-1 Cleanrooms and Associated Controlled Environments - Part 1: Classification of Air Cleanliness. Geneva, Switzerland: ISO;1999, 37p.

[3] Food and Drug Administration. Guidance for Industry. Sterile Drug Products Produced by Aseptic Processing - Current Good Manufacturing Practice. Rockville, MD, USA: FDA; 2004.

[4] Bilan du colloque 'Normes salles Propres ISO 14644', Par Sylvie Vandriessche, 12 janvier 2016, paris France, 1-13 p.

[5] Kumar, Sathish P. "Study and analysis of intrusion detection system using random forest and linear. 